\title{
The Contribution of Surface Electromyographic Assessment for Defining the Stage of Peripheral Facial Paralysis: Flaccid or Sequelae Stage
}

\author{
Daniele Fontes Ferreira Bernardes ${ }^{1}$ Ricardo Ferreira Bento ${ }^{2}$ Maria Valeria Schimidt Goffi Gomez ${ }^{3,4}$ \\ ${ }^{1}$ Department of Otorhinolaryngology, Hospital das Clínicas, \\ Faculdade de Medicina, Universidade de São Paulo (FMUSP), \\ São Paulo, SP, Brazil \\ ${ }^{2}$ Department of Otolaryngology, Universidade de São Paulo, \\ São Paulo, SP, Brazil \\ ${ }^{3}$ Department of Otorhinolaryngology, Hospital das Clínicas da \\ FMUSP, São Paulo, SP, Brazil \\ ${ }^{4}$ Department of Audiology, AC Camargo Cancer Center, São Paulo, \\ SP, Brazil \\ Int Arch Otorhinolaryngol 2018;22:348-357. \\ Address for correspondence Maria Valeria Schimidt Goffi Gomez, \\ Hospital das Clínicas da FMUSP, Av. Dr. Enéas de Carvalho Aguiar, 255 - \\ Departamento de Otorrinolaringologia - 60 andar, São Paulo, SP, \\ 05400301, Brazil (e-mail: valeria.goffi@hc.fm.usp.br).
}

\begin{abstract}
Keywords

- facial paralysis

- electromyography

- surface

Introduction Surface electromyographic activity may not be symmetric, even in subjects with no facial paralysis history.

Objective To evaluate the contribution of the index of electromyographic (IEMG) activity in the identification of the two extremes of the facial paralysis course.

Methods Thirty-four subjects with unilateral peripheral facial paralysis were selected. A control group was composed of volunteers without a history of facial paralysis. The electromyographic assessment of the facial muscle was performed by placing surface electrodes during movements of the forehead, eyes and lips using MIOTEC equipment, such as the MIOTOOL (Miotec, Porto Alegre, Brazil) software. The electromyographic activity was also recorded in other channels during the primary activity to identify the presence of synkinesis. The statistical analysis was performed using the Statistical Package for Social Sciences for Macintosh (SPSS Inc, Chicago, IL, USA). The IEMG activity was obtained from the division of the electromyographic activity root mean square (RMS) values on both sides.

Results There was a statistically significant difference among the groups in all the analyzed indexes. The ocular-oral synkinesis in all patients must be correctly identified (with $100 \%$ sensitivity and specificity) using an IEMG activity of 1.62 as a cutoff point. The oral-ocular synkinesis must be correctly identified (93.3\% sensitivity and $95.9 \%$ specificity) using the IEMG activity of 1.79 as a cutoff point.

Conclusion The IEMG activity is below the normal scores in patients in the flaccid stage, whereas patients in the sequelae stage can either show normal values or values above or below the normal scores. The IEMG activity was shown to have high sensitivity and specificity in the identification of synkinesis.
\end{abstract}

received

March 10, 2017

accepted

September 8, 2017

published online

October 26, 2017
DOI https://doi.org/

$10.1055 / \mathrm{s}-0037-1607335$. ISSN 1809-9777.
Copyright (e) 2018 by Thieme Revinter

Publicações Ltda, Rio de Janeiro, Brazil

License terms

c) $(1) \triangleq \$$ 


\section{Introduction}

The lack of movement and expression on one side of the face, amendments to the way of speaking and, in particular, the impossibility of using the facial mimics have been considered to be among the most flagrant bodily disfigurements since the beginning of humanity. The face reveals the intimacy of our expression and is an essential part of human communication. In addition, contemporary society gives increasing importance to the aesthetics that are directly related to facial appearance because the face is the "site" where we express most of our emotions and its traces define our individuality. ${ }^{1-3}$

The primary function of the facial nerve is to innervate the motor muscles that control facial expression. The nerve, after leaving the temporal bone via the stylomastoid foramen, curves around the styloid process before entering the parotid gland and is divided into peripheral branches to supply the muscles of facial expression. ${ }^{1,4}$

The muscles of facial expression are the most sensitive muscles in the body. They must be observed by a dynamic aspect, under the control of the facial nerve. ${ }^{4}$ The involvement of the seventh nerve causes hypotony of the facial muscles innervated by it, leading to a compromised hemiface ipsilateral to the lesion to a greater or lesser degree. ${ }^{4}$

The degree of facial function recovery depends on the type of lesion (neurapraxia, axonotmesis or neurotmesis), ${ }^{5}$ duration of denervation, motor and sensory connections (direction of the growth of nervous fibers), degree of reinnervation (how many axons regenerate), and state of the muscle. ${ }^{6}$

The evolution of peripheral facial paralysis (PFP) is well defined and occurs in two stages. The initial stage is the flaccid stage, when there is a lack of neural impulse, and the second phase is the sequelae, when the motor recovery is not complete and reinnervation is aberrant. ${ }^{7,8}$ When the paralysis is caused by an iatrogenic lesion, trauma or infectious disease, the possibility of Wallerian degeneration is greater, and the patient's recovery may be accompanied by sequelae inherent to the natural neural regeneration process. ${ }^{9-11}$

The sequelae stage of the PFP is characterized by contractures and synkinesis, defined as involuntary movements accompanying the primary/desired movement. ${ }^{12}$ VanSwearingen $\&$ Brach $^{12}$ emphasize that the synkinesis only occurs on the affected side. May and Schaitkin ${ }^{13}$ describe synkinesis as an aberrant regeneration of the facial nerve that results in a cross-wiring in the muscle motor end plates.

The flaccid stage recovery can be observed by the beginning of facial movements in any facial segment until its complete recovery or the beginning of reinnervation. With axonal reinnervation and the installation of sequelae, myofunctional stimulation may help the patient to minimize the unwanted movements and diminish the contractures, although it will not completely eliminate the sequelae. ${ }^{14,15}$

The degree of involvement and evolution in the motor function of the face is difficult to determine because the assessment methods used for facial evaluation are often subjective and are not capable of demonstrating the actual facial motor condition, whether in the flaccid stage or in the stage of sequelae.
The accurate determination of the degree of motor impairment of the face is an important part in the evaluation of patients with PFP and interferes with therapeutic decisions in each case. Thus, the evolution of patients must be monitored properly, and the response to the treatment must be evaluated more closely. $^{16-18}$

Several rehabilitation centers of the facial nerve are interested in the use of clinical evaluation tools to try to classify facial paralysis in the most accurate way. House and Brackmann ${ }^{19}$ proposed facial nerve grading system, which is currently recommended by the American Academy of Otorhinolaryngology and Head and Neck Surgery. Ross, Fradet and Nedzelski ${ }^{20}$ presented a protocol called the Facial Grading System (FGS), which assesses the clinical signs obtained at rest, during the facial individual functions, as well as the presence of synkinesis. This is widely documented in the scientific arena that addresses facial paralysis topics. ${ }^{10,14,21}$

In search of objective ways to identify minimal variations in muscular activity and to optimize the development of non-surgical treatment of PFP, many studies have been performed using surface electromyography (EMG) biofeedback. Brach and Vanswearingen, ${ }^{21}$ Diels, ${ }^{10}$ Henkelmann and May, ${ }^{22}$ Nakamura et al, ${ }^{23}$ Cronin and Steenerson ${ }^{24}$ and Novak $^{14}$ used the technique of biofeedback EMGs in the rehabilitation process of patients with facial paralysis but did not mention using the muscular activity measurement as a clinical evaluation tool.

Vanswearingen $^{3}$ reported that the EMG biofeedback may be used in the muscular reeducation treatment of PFP for the observation of subtle movements or, even in the absence of movements, to provide precise and immediate feedback about the patient's attempts to increase the facial muscle activity.

Bernardes and Franco ${ }^{25}$ associated the technique of EMG biofeedback for the aesthetic stimulation of the face with the objective to restore the symmetry of smile in a patient with sequela of PFP on the left side. After 10 sessions of EMG biofeedback, the mean of the root mean square (RMS) of the left depressor of the lower lip fell to $16 \mu \mathrm{V}$, almost achieving the mean of the right depressor of the lower lip of $14 \mu \mathrm{V}$. The left zygomatic muscles showed an increase in the mean to $22 \mu \mathrm{V}$, and the right zygomatic muscles showed a mean RMS of $21 \mu \mathrm{V}$, thus proving the asymmetry of the amplitudes of the activity in the stimulated muscles.

The use of EMG biofeedback as adjuvant in the treatment of facial paralysis is already enshrined; nevertheless, the value of the electromyographic activity of mimic muscles in cases of PFP and its contribution to the diagnosis and follow up are minimally explored in the literature.

Surface EMG records the electrical activity of the muscles beneath a pair of recording electrodes (Vanswearingen and Brach). ${ }^{12}$

The use of EMGs is relatively recent in the field of speech therapy, having as an objective the diagnosis and treatment of oral motor difficulties in cases of swallowing, chewing and speech disorders. ${ }^{26-33}$

Since EMG is a painless and noninvasive examination and the surface electrodes are positioned on the skin, it allows the patients to execute the movement or requested function in a 
natural way. In addition, it allows repetition, which is of great value in the monitoring of orofacial myofunctional therapies. ${ }^{34}$

Although surface EMG has proven to be important for evaluating several diseases within the framework of the orofacial myology, the electromyographic profile of the mimic muscles in facial paralysis cases has not been fully explored.

\section{Objectives}

To evaluate the pattern of electromyographic activity in the normal and affected hemiface in cases of PFP in its two stages: muscle without neural supply (flaccid stage) and muscle after aberrant neural regeneration (sequelae stage);

To assess the relationship of electromyographic activity between the sides of the face in cases of PFP and in normal individuals; and to determine whether the electromyographic activity ratio between the face halves can be used to identify the presence of synkinesis.

\section{Methods}

\section{Sample Features}

Subjects diagnosed with PFP who met the following criteria were studied:

Inclusion criteria:

- Unilateral peripheral facial paralysis of any etiology;

- Ages ranging from 18 to 69 years;

- Both genders;

- Subjects who had been assisted in the walk-in clinic of facial paralysis in the speech therapy group of the division of ENT at a tertiary hospital during the period between January and December of 2006.

Exclusion criteria:

- Previous facial paralysis history;

- Congenital PFP;

- Presence of a beard;

- Facial lesions or scars that may interfere with the electrodes' contact.

Thirty-four individuals met the criteria. The control group was composed of volunteers without a history of facial paralysis, face trauma or craniofacial anomalies.

In addition to the patients with facial paralysis, we evaluated a control group of 20 volunteers without a history of facial paralysis using the same EMG protocol.

This study was submitted and approved by the Commission for the Analysis of Research Project (CAPPesq in the Portuguese acronym) under protocol $\mathrm{N}^{\circ} 313 / 05$. The patients were informed of the aim of the study and included in it after providing a signed informed consent.

\section{Procedures}

The patients with PFP and the control group were submitted to the following procedures:

Classification of House-Brackman (HB)

Surface EMG
The same examiner classified all subjects and performed the EMGs always in the mornings and in the same room.

\section{Clinical Classification}

The clinical condition of the facial muscle was classified by HB $(1985)^{19}$ on the same day as the electromyographic evaluation was performed. The selected subjects and volunteers were distributed into three groups after the classification using the HB scale:

Group 1 (flaccid stage): patients with PFP in the flaccid stage (lack of neural information) and HB V or VI;

Group 2 (sequelae stage): patients with PFP in the stage of sequelae (reinnervated muscle), with onset time $\geq 90$ days and HB III or IV.

Control Group: individuals without antecedent of PFP and HB I.

In addition to the $\mathrm{HB}$ classification, the presence of synkinesis was identified during primary movements of eyes closure, puckering of lips and lip retraction. To identify accompanying abnormal movements, the intended movement of all segments (forehead, eye, nose, and lip) of the affected hemiface was observed during each primary movement.

\section{Surface Electromyographic Assessment}

The assessment of electric activity of the face muscles was performed using a 4-channel MIOTEC equipment (Miotec, Porto Alegre, Brazil) with MIOTOOL software (Miotec, Porto Alegre, Brazil), a low-pass filter, and disposable silver/silver chloride $(\mathrm{Ag} / \mathrm{AgCl})$ mini med Kendall surface electrodes (Medtronic, Minneapolis, MN, USA).

Subjects were examined while comfortably seated on a vertical backrest chair with their feet resting on a rubber carpet. A pair of surface electrodes were adhered to the skin over the region of frontalis, orbicularis oculi, orbicularis oris and elevator of lip/zygomatic muscle with the following arrangement: the electrodes were placed on the forehead (frontalis muscle), one on each side of the face, at $2 \mathrm{~cm}$ above the eyebrows, aligned vertically at the midline of the eyeball; on the orbicularis oculi muscle, one on each side of the face, at $5 \mathrm{~mm}$ from the external end of the eyes; and on the orbicularis oris muscle, one on each side of the face, at $2 \mathrm{~mm}$ from the corner of the mouth accompanying the nasolabial fold. The electrodes on the region of the elevator of lip/ zygomatic muscles, one on each side of the face, were placed at $1 \mathrm{~cm}$ from the corner of the mouth tilted toward the external corner of the eyes.

A unipolar reference electrode was placed over the right sternocleidomastoid muscle.

The following movements were requested for the recording of surface electromyographic activity:

- Raising the eyebrows;

- Forced eye closure,

- Lip protrusion (puckering)

- Lip retraction (smile)

In addition, electromyographic activity was recorded in other channels corresponding to the associated movements 
during the primary activity to identify the presence of synkinesis.

- activity of the lips during the eye closure

- activity of the eyes during the lip protrusion

- activity of the eyes during the lip retraction

For each test, the patient was requested to make the movement in maximal effort, and the EMG was recorded for 8 seconds. The mean of the action potentials in micro volts ( $\mu v$ ) during the 8 seconds of each isometric contraction was calculated by software as the RMS.

\section{Statistical Analysis}

The statistical analysis was performed using the software Statistical Package for Social Sciences (SPSS) for Macintosh (SPSS Inc, Chicago, IL, USA). The mean value (in $\mu \mathrm{V}$ ) obtained during the 8-second recording window was considered as the electromyographic activity of each segment of the hemiface (forehead, eye and lip) during each movement (raising eyebrows, closing eyes, lip protrusion and lip retraction).

The IEMG activity was calculated based on the electromyographic activity of the affected side divided by the activity of the normal side.

Quantitative Analysis: The mean values of the IEMG activity between the flaccid stage, stage of sequela and control groups were compared using a one-way analysis of variance (ANOVA). The normal distribution (Gaussian) of the data was confirmed by the Kolmogorov-Smirnov test. The post hoc analysis was performed using the Tukey multiple comparisons test to identify the groups between which there was a difference.

Qualitative Analysis: Normal IEMG activity values were obtained by studying the control group and these were calculated by dividing the activity of the left by the activity of the right side. Normal values were considered those between the 5 (p5) and 95 (p95) percentiles, excluding the outliers. The normal IEMG activity interval for each segment during each movement was compared within the study groups. The values of IEMG activity found in patients in the facial paralysis groups were classified as "low" or "high" when they were, respectively, below or above the interval included in -Table 1 for each situation. The prevalence of patients with normal, low or high IEMG activity was compared between groups with facial paralysis (flaccid stage and sequela) using the Chi-square test.

For both qualitative and quantitative analyses, statistically significant differences were considered when $p$ values were lower than 0.05 (5\%). The accuracy of the IEMG activity in the identification of synkinesis was determined.

Data for all subjects (including controls) were separated according to the presence of synkinesis for each analyzed movement. A receiver operator characteristics (ROC) curve was constructed to identify the ideal cutoff point of the IEMG for the identification of synkinesis. The ideal point was set at the value that simultaneously presented the sensitivity and specificity closest to $100 \%$.
Table 1 Demographic data of the sample analyzed in the flaccid stage, sequelae stage and control groups

\begin{tabular}{|l|l|l|l|}
\hline \multicolumn{1}{|l|}{} & $\begin{array}{l}\text { Group 1 } \\
\text { Flaccid } \\
\text { stage } \\
(N=17)\end{array}$ & $\begin{array}{l}\text { Group 2 } \\
\text { Sequelae } \\
\text { stage } \\
(N=17)\end{array}$ & $\begin{array}{l}\text { Control } \\
\text { Group } \\
(N=20)\end{array}$ \\
\hline Age (Years) & $37.6( \pm 13.2)$ & $48.1( \pm 10.0)$ & $42.1( \pm 16.5)$ \\
\hline $\begin{array}{l}\text { Time since } \\
\text { the onset } \\
\text { of PFP } \\
\text { (months) }\end{array}$ & $6.5( \pm 10.1)$ & $22.0( \pm 17.3)$ & - \\
\hline Etiology & \multicolumn{5}{|l}{} \\
\hline Idiopathic & $11(64.7 \%)$ & $9(52.9 \%)$ & - \\
\hline Traumatic & $6(35.3 \%)$ & $8(47.1 \%)$ & - \\
\hline Side of Paralysis & $7(41.0 \%)$ & $5(29.0 \%)$ & - \\
\hline Right & $10(59.0 \%)$ & $12(71.0 \%)$ & - \\
\hline Left & - & - & $20(100 \%)$ \\
\hline HB Grade & - & $7(41.0 \%)$ & - \\
\hline I & - & $10(59.0 \%)$ & - \\
\hline III & $4(23.5 \%)$ & - & - \\
\hline IV & $13(76.5 \%)$ & & - \\
\hline V & - & \\
\hline VI & & \\
\hline
\end{tabular}

Abbreviations: HB, House-Brackman; PFP, Peripheral Facial Paralysis. Data presented as mean ( \pm standard deviation) or $\mathrm{N}(\%)$.

\section{Results}

Demographic data of the sample are presented in - Table 1 and show that the distribution of age between the groups is similar.

The normal IEMG activity interval for each segment during each movement is presented in - Table 2.

All 34 (100\%) patients with PFP underwent myofunctional treatment at the walk-in clinic of speech therapy for facial paralysis in a tertiary hospital.

Table 2 Normal range of IEMG activity for each segment in each movement obtained in the control group

\begin{tabular}{|l|l|l|}
\hline Movement & $\begin{array}{l}\text { Segment of } \\
\text { electromyographic } \\
\text { activity register }\end{array}$ & $\begin{array}{l}\text { Normal range } \\
\text { of the IEMG } \\
\text { activity }\end{array}$ \\
\hline Raising eyebrows & Eyebrows & $0.59-1.39$ \\
\hline \multirow{2}{*}{ Eye closure } & Eyes & $0.59-1.28$ \\
\cline { 2 - 3 } & Lips & $0.47-1.55$ \\
\hline \multirow{2}{*}{ Lip puckering } & Lips & $0.79-1.28$ \\
\cline { 2 - 3 } & Eyes & $0.51-1.45$ \\
\hline \multirow{2}{*}{$\begin{array}{l}\text { Smile } \\
\text { (lip retraction) }\end{array}$} & Lips & $0.64-1.28$ \\
\cline { 2 - 3 } & Eyes & $0.71-1.58$ \\
\hline
\end{tabular}

Abbreviation: IEMG, index of electromyographic activity. 1: Interval between percentile $\mathrm{p} 5$ and $\mathrm{p} 95$. 
Table 3 Index of electromyographic activity averages of each segment of the face evaluated in the three groups studied

\begin{tabular}{|c|c|c|c|c|c|}
\hline Movement & $\begin{array}{l}\text { Segment of electromyographic } \\
\text { activity register }\end{array}$ & $\begin{array}{l}\text { Group } 1 \\
\text { Flaccid stage } \\
(N=17)\end{array}$ & $\begin{array}{l}\text { Group } 2 \\
\text { Sequelae stage } \\
(N=17)\end{array}$ & $\begin{array}{l}\text { Control } \\
(N=20)\end{array}$ & $p$ \\
\hline Raise eyebrows & Eyebrows & $0.23 \pm 0.09^{a}$ & $0.66 \pm 0.38^{b}$ & $1.0 \pm 0.23^{c}$ & $<0.001$ \\
\hline \multirow[t]{2}{*}{ Eye closure } & Eyes & $0.29 \pm 0.19^{a}$ & $0.67 \pm 0.34^{b}$ & $0.89 \pm 0.28^{c}$ & $<0.001$ \\
\hline & Lips & $0.60 \pm 0.32^{a}$ & $2.11 \pm 0.85^{b}$ & $1.11 \pm 0.28^{c}$ & $<0.001$ \\
\hline \multirow[t]{2}{*}{ Lip puckering } & Lips & $0.30 \pm 0.11^{a}$ & $0.60 \pm 0.22^{b}$ & $1.04 \pm 0.18^{c}$ & $<0.001$ \\
\hline & Eyes & $0.80 \pm 0.35^{a}$ & $2.59 \pm 0.89^{b}$ & $0.95 \pm 0.42^{a}$ & $<0.001$ \\
\hline \multirow[t]{2}{*}{ Smile } & Lips & $0.22 \pm 0.12^{a}$ & $0.71 \pm 0.69^{b}$ & $0.99 \pm 0.18^{b}$ & $<0.001$ \\
\hline & Eyes & $0.37 \pm 0.17^{a}$ & $0.98 \pm 0.43^{b}$ & $1.04 \pm 0.27^{b}$ & $<0.001$ \\
\hline
\end{tabular}

Legend: a, b, c letter indices identify statistically significant differences found between the averages of groups (multiple comparisons test of Tukey).

Each subject with PFP was submitted to an electromyographic evaluation after 6.5 months (+10.14 days) of the paralysis onset for the flaccid stage group and 22 months ( +17.30 days) for the sequela stage group.

The means and standard deviations of the IEMG activity of each segment are presented in - Table $\mathbf{3}$ and represented graphically in - Figs. 1 to $\mathbf{4}$. - Table $\mathbf{3}$ shows that there were statistically significant differences between the groups in all the movements analyzed. In the post hoc analysis, the identification of equal letters shows that there was no statistically significant difference between the flaccid stage and control groups for the eye during lip protrusion and between the sequela stage and control groups for the eye and lip during lip retraction. All the differences between the groups in other situations were statistically significant.

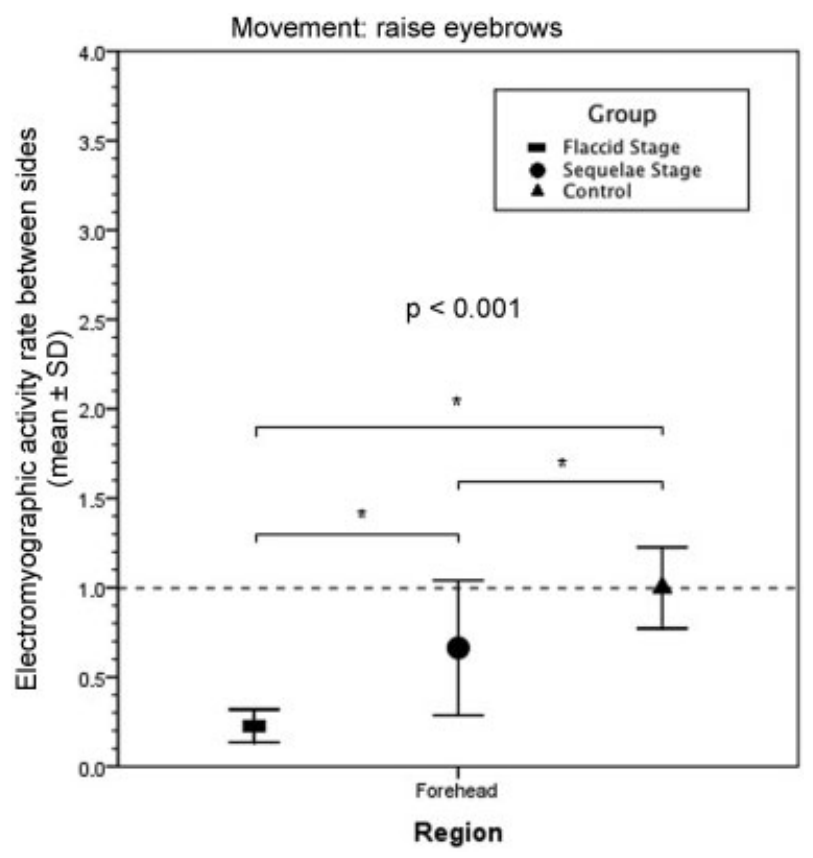

Fig. 1 Error bars representing the mean and the standard deviation of the IEMG activity of the movement raising the eyebrows in the studied groups.
- Tables 4 to 7 show that the primary IEMG activity at the forehead, eyes, lip protrusion and retraction are below the normal IEMG activity (control group) in $100 \%$ of the patients in the flaccid stage, with the exception of the movement of the eyes $(88.2 \%)$. In the group of patients in the sequelae stage, it was observed that the presence of high IEMG activity of those associated movements occurred mainly in the eye closure and lip protrusion.

- Accuracy of the IEMG activity for the identification of synkinesis

Among all the 54 sample subjects (PFP and controls), 13 (24.1\%) presented clinically detected synkinesis of the lip during eye closure and 15 (27.8\%) presented synkinesis detected in the eye during the lip protrusion. All the subjects

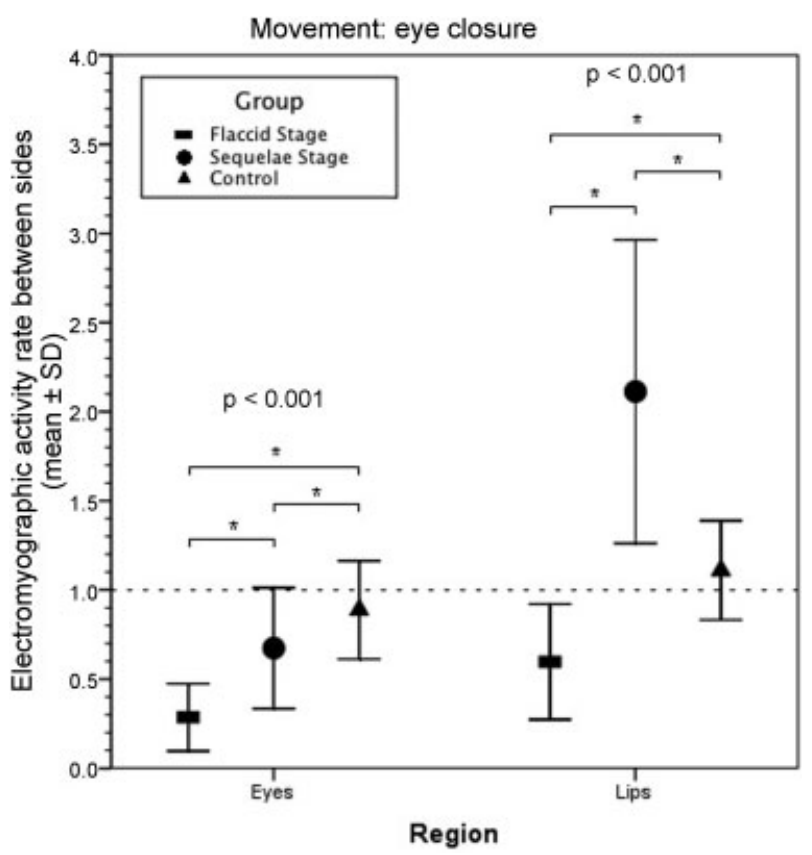

Fig. 2 Error bars representing the mean and the standard deviation of the IEMG activity of the movement of eye closure in the studied groups. 
Contribution of Surface Electromyographic Assessment to PFP Stage Bernardes et al. 353

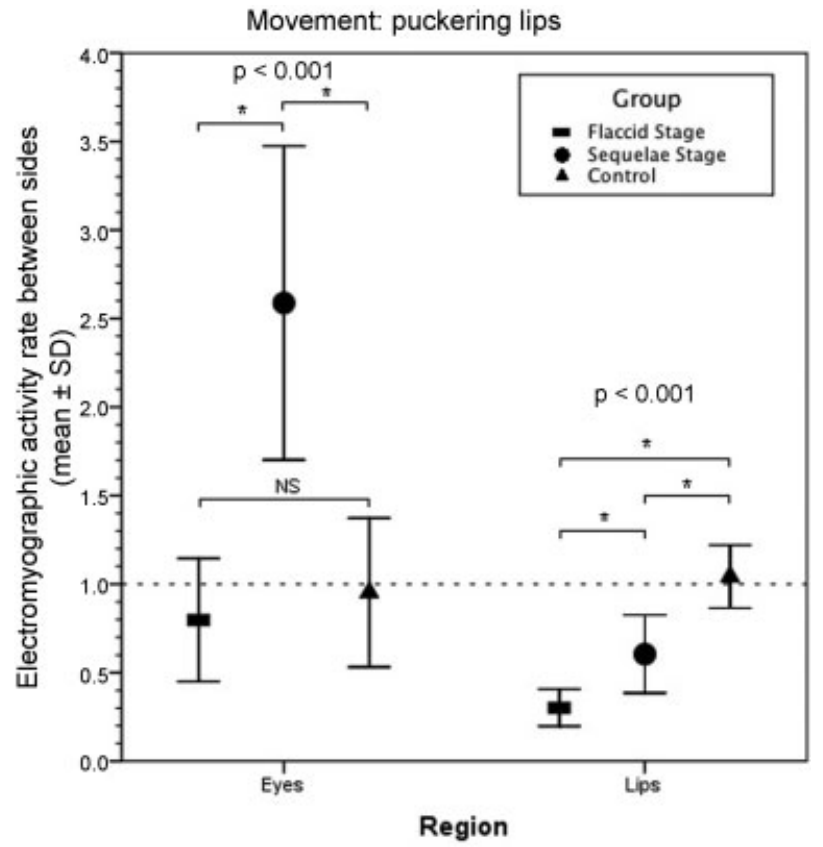

Fig. 3 Error bars representing the mean and the standard deviation of the IEMG activity of the movement of puckering lips in the studied groups.

with synkinesis belonged to the facial paralysis-sequela stage group, and all the individuals in this group presented synkinesis in at least one of the movements.

The IEMGs activity between subjects with and without synkinesis are presented in - Table 8.

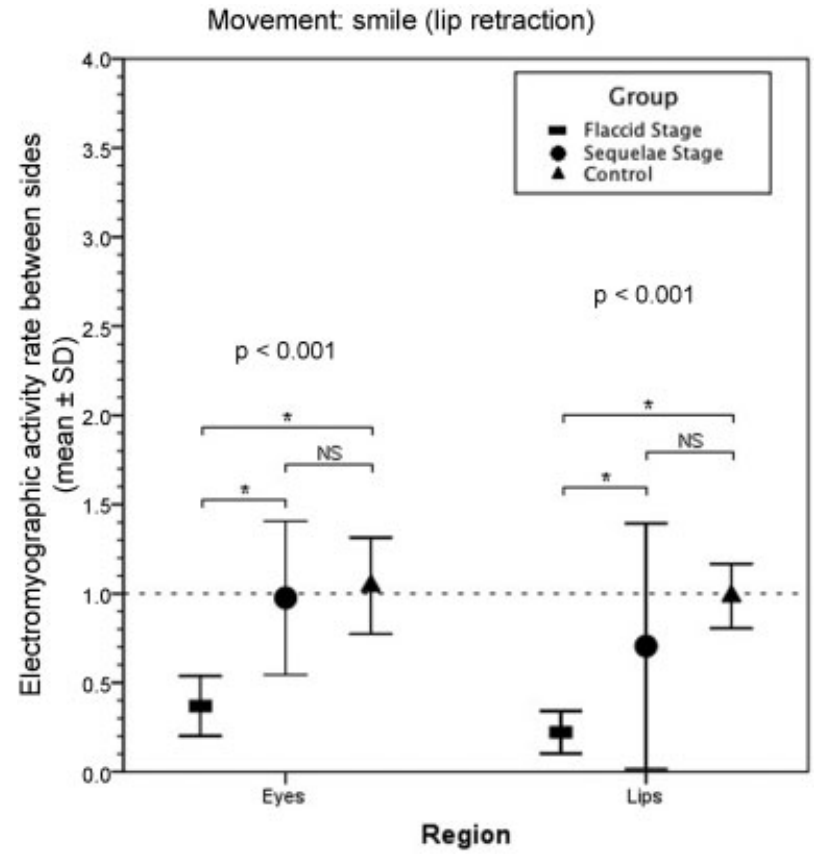

Fig. 4 Error bars representing the mean and the standard deviation of the index of electromyographical activity in the movement of lip retraction in the studied groups.

- Fig. 5 shows the ROC curve for the identification of synkinesis on the lip during eye closure (ocular-oral) through the IEMG activity. It shows that overall, individuals will be correctly diagnosed (with 100\% true positive and $0 \%$ false negative) when using an IEMG activity value of 1.62 as the cutoff point.

Table 4 Prevalence of patients with normal, low or high index of electromyographic activity in the eyebrows segment in both studied groups

\begin{tabular}{|l|l|l|l|l|l|}
\hline Movement & $\begin{array}{l}\text { Segment or electromyographic } \\
\text { activity register }\end{array}$ & $\begin{array}{l}\text { Electromyographic } \\
\text { activity }\end{array}$ & $\begin{array}{l}\text { Group 1 } \\
\text { Flaccid stage } \\
(N=17)\end{array}$ & $\begin{array}{l}\text { Group } 2 \\
\text { Sequelae stage } \\
(N=17)\end{array}$ & $\begin{array}{l}p \\
\text { s }\end{array}$ \\
\hline Raising eyebrows & Eyebrows & Low & $17(100 \%)$ & $7(41.2 \%)$ & \\
\hline & & Normal & $0(0.0 \%)$ & $9(52.9 \%)$ & 0.001 \\
\hline & & High & $0(0.0 \%)$ & $1(5.9 \%)$ \\
\hline
\end{tabular}

Table 5 Prevalence of patients with normal, low or high index of electromyographic activity in the eyes segment in both studied groups

\begin{tabular}{|c|c|c|c|c|c|}
\hline Movement & $\begin{array}{l}\text { Segment or electromyographic } \\
\text { activity register }\end{array}$ & $\begin{array}{l}\text { Electromyographic } \\
\text { activity }\end{array}$ & $\begin{array}{l}\text { Group } 1 \\
\text { Flaccid stage } \\
(N=17)\end{array}$ & $\begin{array}{l}\text { Group } 2 \\
\text { Sequelae stage } \\
(N=17)\end{array}$ & $p$ \\
\hline \multirow[t]{6}{*}{ Eye closure } & \multirow[t]{3}{*}{ Eyes } & Low & $15(88.2 \%)$ & 7 (41.2\%) & \multirow[t]{3}{*}{05} \\
\hline & & Normal & $2(11.8 \%)$ & $9(52.9 \%)$ & \\
\hline & & High & $0(0.0 \%)$ & 1 (5.9\%) & \\
\hline & \multirow[t]{3}{*}{ Lips } & Low & 7 (41.2\%) & $0(0.0 \%)$ & \multirow[t]{3}{*}{$<0.001$} \\
\hline & & Normal & $10(58.8 \%)$ & $3(17.6 \%)$ & \\
\hline & & High & $0(0.0 \%)$ & $14(82.4 \%)$ & \\
\hline
\end{tabular}


354 Contribution of Surface Electromyographic Assessment to PFP Stage Bernardes et al.

Table 6 Prevalence of patients with normal, low or high index of electromyographic activity during lip protrusion in both studied groups

\begin{tabular}{|c|c|c|c|c|c|}
\hline \multirow[t]{2}{*}{ Movement } & \multirow{2}{*}{$\begin{array}{l}\text { Segment or electromyographic } \\
\text { activity register }\end{array}$} & \multirow{2}{*}{$\begin{array}{l}\text { Electromyographic } \\
\text { activity }\end{array}$} & \multicolumn{2}{|l|}{ Group } & \multirow[t]{2}{*}{$p$} \\
\hline & & & $\begin{array}{l}\text { Paralysis } \\
\text { Flaccid stage } \\
(N=17)\end{array}$ & $\begin{array}{l}\text { Paralysis } \\
\text { Sequelae stage } \\
(N=17)\end{array}$ & \\
\hline \multirow[t]{6}{*}{ Lip puckering } & \multirow[t]{3}{*}{ Lips } & Low & 17 (100\%) & $14(82.4 \%)$ & \multirow[t]{3}{*}{0.23} \\
\hline & & Normal & $0(0.0 \%)$ & $3(17.6 \%)$ & \\
\hline & & High & $0(0.0 \%)$ & $0(0.0 \%)$ & \\
\hline & \multirow[t]{3}{*}{ Eyes } & Low & 1 (5.9\%) & $0(0.0 \%)$ & \multirow[t]{3}{*}{$<0.001$} \\
\hline & & Normal & 14 (82.4\%) & 1 (5.9\%) & \\
\hline & & High & $2(11.8 \%)$ & 16 (94.1\%) & \\
\hline
\end{tabular}

Table 7 Prevalence of patients with normal, low or high index of electromyographic activity in the lips segment in both studied groups

\begin{tabular}{|c|c|c|c|c|c|}
\hline & \multirow{2}{*}{$\begin{array}{l}\text { Segment or electromyographic } \\
\text { activity register }\end{array}$} & \multirow{2}{*}{$\begin{array}{l}\text { Electromyographic } \\
\text { activity }\end{array}$} & \multicolumn{2}{|l|}{ Group } & \multirow[t]{2}{*}{$p$} \\
\hline & & & $\begin{array}{l}\text { Paralysis } \\
\text { Flaccid stage } \\
(N=17)\end{array}$ & $\begin{array}{l}\text { Paralysis } \\
\text { Sequelae stage } \\
(N=17)\end{array}$ & \\
\hline \multirow[t]{6}{*}{ Smile (lip retraction) } & \multirow[t]{3}{*}{ Lips } & Low & $17(100 \%)$ & 12 (70.6\%) & \multirow[t]{3}{*}{0.05} \\
\hline & & Normal & $0(0.0 \%)$ & $3(17.6 \%)$ & \\
\hline & & High & $0(0.0 \%)$ & $2(11.8 \%)$ & \\
\hline & \multirow[t]{3}{*}{ Eyes } & Low & $17(100 \%)$ & $7(41.2 \%)$ & \multirow[t]{3}{*}{0.001} \\
\hline & & Normal & $0(0.0 \%)$ & $7(41.2 \%)$ & \\
\hline & & High & $0(0.0 \%)$ & $3(17.6 \%)$ & \\
\hline
\end{tabular}

Table 8 Index of electromyographic activity between subjects with and without synkinesia in the segment of lips and eyes

\begin{tabular}{|l|l|l|l|l|l|l|}
\hline Movement & Segment or electromyographic & \multicolumn{2}{|l|}{ Synkinesis } & \multicolumn{2}{l|}{$\boldsymbol{N}$} \\
\cline { 3 - 7 } & activity register & & Yes & & No \\
\cline { 3 - 7 } & & $\mathbf{N}$ & Index & $\mathbf{N}$ & Index \\
\hline Eye closure & Lips & 13 & $2.43 \pm 0,67$ & 41 & $0.89 \pm 0.40$ & $<0.001$ \\
\hline Puckering lips & Eyes & 15 & $2.73 \pm 0.84$ & 39 & $0.91 \pm 0.41$ & $<0.001$ \\
\hline
\end{tabular}

Abbreviation: EMG,

-Fig. 6 shows the ROC curve for the identification of synkinesis of the eye during the lip protrusion (oral-ocular). As shown in the curve and in - Table 9, the IEMG activity cutoff point that presents the highest sensitivity and specificity is 1.79 .

\section{Discussion}

According to Coulson et $\mathrm{al}^{17}{ }^{17}$ Linstrom, ${ }^{18}$ and Mitre et $\mathrm{al},{ }^{35}$ an evaluation method that has clinical utility must be objective, must allow different examiners to obtain the same results for a given patient at a given time, and must be sufficiently sensitive to detect subtle clinical changes. It would be even better if the method was easy to perform and required little equipment. The EMG proved to be an objective method that is sufficiently easy to use and sensitive to detect different stages in the course of PFP.
An electromyography that uses needles in the muscle as recording electrodes to assess the electrical activity of the facial neuromuscular system may incur some discomfort and pain, which may prevent facial muscles from moving naturally. ${ }^{36}$ The surface EMG used in this study allowed the patient to perform the movements required to assess facial musculature in accordance with the guidance proposed by Ohyama et al. ${ }^{37}$

At the beginning of the disease and during the course of the paralysis, when neural impulses are absent, the person is unable to move the face. The EMG showed that at this stage, the IEMG activity varied from 0.22 to 0.80 . When the degree of injury to the facial nerve is severe (axonotmesis or neurotmesis), as the axons regenerate, they may enter the incorrect tubes, and synkinesis may develop (Cronin and 


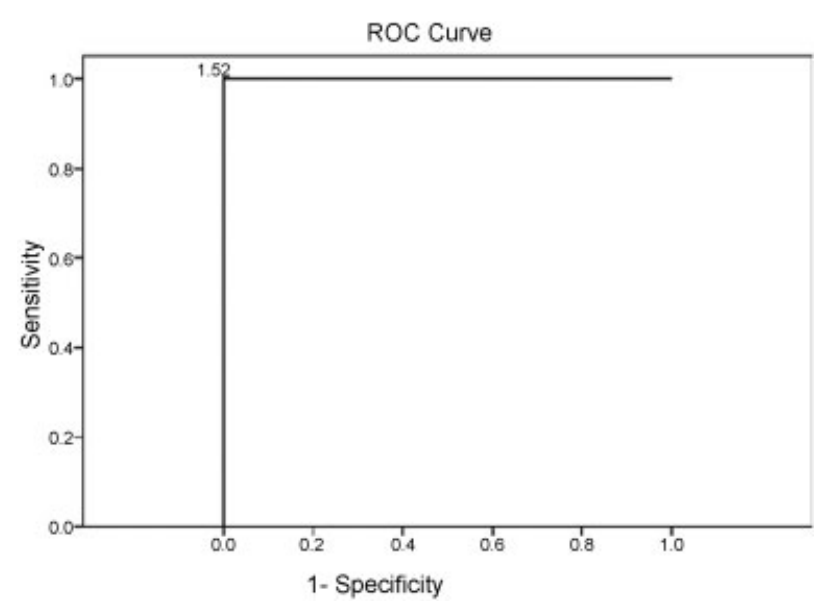

Fig. 5 Receiver operator characteristics (ROC) curve for the clinical diagnosis of synkinesis in lips during the movement of eyes closure (ocular-oral) through index of electromyographical activity.

Steenerson, 2003). ${ }^{24}$ At this stage, the EMG results showed that the IEMG activity varied from 0.60 to 2.59 .

Wood $^{38}$ noted that there is a great variability between the sides of the face in normal individuals. Scriba et $\mathrm{al}^{16}$ also found a physiological asymmetry ranging from 7 to $9 \%$ in facial movements in normal individuals. In our study, the IEMG activity (between the 5th and 95th percentiles) of normal subjects with no history of facial nerve injury that presented the greatest variation was the movement of lips (0.47-1.55). We attribute this to the fact that lip movement is one of the widest movements in the facial expression and each individual exerts a specific muscle strength. Although the instruction to all subjects was to perform the movement with maximum effort, each individual interprets this order in accordance with her/his pattern of muscle strength.

According to the findings of Pennock (1999), ${ }^{39}$ there is a great variation between the muscle activity and the movement exerted by the individual.

This is one of the reasons why using absolute values to characterize electromyographic activity is not advisable, given the influence of factors such as the exerted strength in addition to the position of electrodes, among other aspects. Under such consideration, in this work, we suggest the use of the IEMG activity, which is a relative index between the hemifaces.

On et $\mathrm{al}^{40}$ found that the EMG surpassed the clinical evaluation in the identification of subtle facial movements that were not observed clinically.

Although their study used needle electrodes, their results are in accordance with ours, in which synkinesis could be identified through EMGs in all the patients who were clinically classified as being at the stage of sequelae. In addition, the use of EMGs made it possible to determine the ideal cutoff point for the IEMG activity for use in the diagnosis of synkinesis. For lip synkinesis during eye closure, all of the individuals were identified correctly (with $100 \%$ true positive and $0 \%$ false negative) using an IEMG activity with 1.62 as the cutoff point. For the identification of synkinesis in the

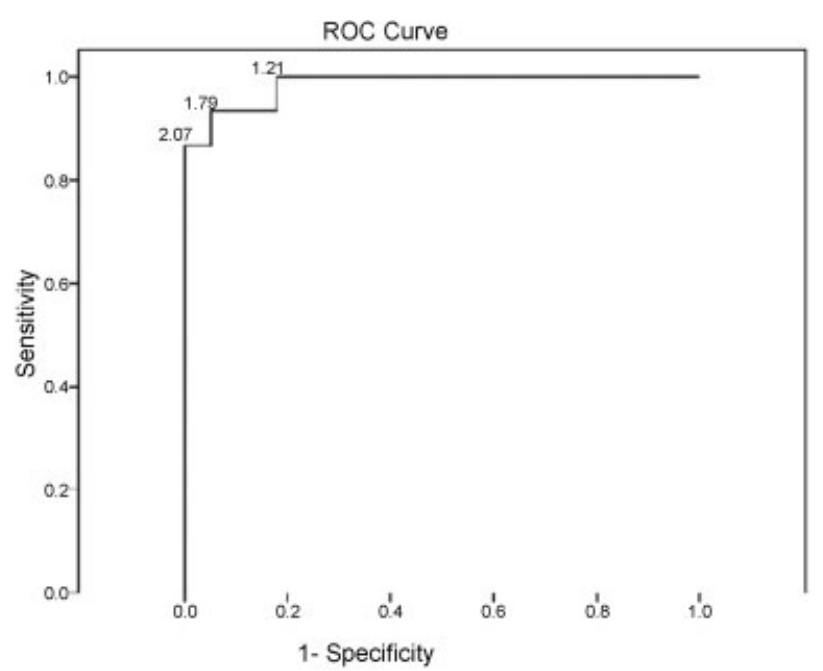

Fig. 6 Receiver operator characteristics (ROC) curve of the index of electromyographic activity using different cutoff points for clinical identification of synkinesis in the eyes during the movement of puckering lips (oral-ocular).

eye during lip protrusion, the cutoff point of the IEMG activity at which the greatest sensitivity (93.3\%) and specificity (95.9\%) were revealed was 1.79 .

In this study, the EMGs were capable of identifying the stages of the course of the PFP, showing statistically significant differences among the means of the IEMG activity of the three studied groups in all movements, except in the flaccid stage and the control group, where the primary movement was lip protrusion and the analyzed segment was the eye. In these two groups, the electric signal was not recorded in the eye segment during lip protrusion (puckering) because the eyes are not involved in the primary movement; thus, both groups had equal actions in the eyes. In contrast, in the sequelae group, the presence of ocular-oral synkinesis was detected by EMGs, as described by Vanswearingen and Brach (2003). ${ }^{12}$ For example, a person with unilateral ocular-oral synkinesis will demonstrate an abnormal action of the lips on the affected side during the closure of the eyes.

Table 9 Cutoff point that presents at the same time greater sensitivity and specificity

\begin{tabular}{|l|l|l|}
\hline Cutoff point & Sensitivity & Specificity \\
\hline 1.21 & $100 \%$ & $82.1 \%$ \\
\hline 1.33 & $93.3 \%$ & $82.1 \%$ \\
\hline 1.48 & $93.3 \%$ & $84.6 \%$ \\
\hline 1.51 & $93.3 \%$ & $87.2 \%$ \\
\hline 1.52 & $93.3 \%$ & $89.7 \%$ \\
\hline 1.64 & $93.3 \%$ & $92.3 \%$ \\
\hline 1.79 & $93.3 \%$ & $95.9 \%$ \\
\hline 1.89 & $86.7 \%$ & $95.9 \%$ \\
\hline 1.98 & $86.7 \%$ & $97.4 \%$ \\
\hline 2.07 & $86.7 \%$ & $100 \%$ \\
\hline
\end{tabular}


In our study, we found that the difference between the sequelae and the control groups when recording lip retraction as the primary movement and the eye as secondary movement (abnormal) was not statistically significant.

This movement with maximum effort naturally involves the compensatory reaction of zygomaticus and lip elevator muscles on both sides of the face, thus generating wrinkles of expression around the eyes. Since the facial nerve reinnervation has already occurred in the sequelae group, it is expected that zygomaticus/elevator muscles are activated during this movement; thus, the muscle activity is recorded in the electrode segment of the eyes in a similar way as in the control group. It is important to highlight that the synkinetic movements observed as sequelae of a facial paralysis are observed exclusively in the affected side.

When we analyzed the IEMG activity in the flaccid stage group, we observed that there was a prevalence of low IEMGs activity in all movements - lifting the forehead (100\%), eye closure (88.2\%), lip protrusion (100\%) and lip retraction (100\%) - correlated with the clinical assessment of patients. In contrast, the analysis of the IEMG activity in the sequelae stage group showed that there was a prevalence of normal IEMG activity in raising the eyebrow (52.9\%) and eye closure (52.9\%), despite a high IEMG activity of the associated movement on the lips (82.4\%), thus demonstrating an ocular-oral synkinesis.

In relation to lip protrusion, both the flaccid and the sequelae stage groups showed low IEMG activity, with a prevalence of $100 \%$ for the flaccid stage and $82.4 \%$ for the sequelae stage. However, for the same movement (lip protrusion), the associated movement in the eye showed a high IEMG activity of $94.1 \%$ in the patients in the sequelae stage group. Interestingly, the IEMG activity value of the synkinesis was above the primary IEMG activity value for the primary movement itself, which demonstrates a remarkable action of the eye in an oral-ocular synkinesis.

Lip retraction also showed a low IEMG activity in the two studied groups, with a prevalence of $100 \%$ for the flaccid stage group and $70.6 \%$ for the sequelae stage group. Nevertheless, for the sequelae stage group, a normal IEMG activity was found in $17.6 \%$ of the patients, and a high IEMG activity was found in $11.8 \%$. These findings show that the smile has an important social function and is among the movements with the lowest rate of recovery, even after evident reinnervation.

The proper treatment of PFP implies a precise diagnosis. The clinical assessment of the orofacial motricity must be combined with an objective examination that should be replicated throughout the course of the disease, thus allowing the proper follow up. In this way, the treatment may also be determined based on objective data.

Surface EMG proved to be an objective assessment tool that is capable of differentiating both stages of the evolution of facial paralysis and identifying the synkinesis.

\section{Conclusion}

The pattern of electromyographic activity showed to be significantly different between the groups in the flaccid and the sequelae stages.
The relationship between the two hemifaces is below the normal pattern in patients in the flaccid stage and may show normal, high or below-pattern values in individuals at the stage of sequelae.

The IEMG activity showed to be of high sensitivity and specificity in the identification of sequelae.

\section{References}

1 Bento RF. Doenças do Nervo Facial. In: Bento RF, Miniti A, Marone S. Tratado de Otologia. São Paulo: Edusp; 1998:427-459

2 Lazarini PR, Costa HJZR, Camargo ACK. Anatomo-fisiologia e fisiopatologia do Nervo Facial. In: Lazarini PR, Fouquet ML. Paralisia Facial Avaliação Tratamento Reabilitação. São Paulo: Lovise; 2006:25-32

3 Vanswearingen J. Facial rehabilitation: a neuromuscular reeducation, patient-centered approach. Facial Plast Surg 2008;24 (02):250-259

4 Rosson GD, Redett RJ. Facial palsy: anatomy, etiology, grading, and surgical treatment. J Reconstr Microsurg 2008;24(06):379-389

5 Sunderland S. The anatomy and physiology of nerve injury. Muscle Nerve 1990;13(09):771-784

6 Irintchev A, Wernig A. Denervation and reinnervation of muscle: physiological effects. Eur Arch Otorhinolaryngol 1994(Suppl): S28-S30

7 Moran CJ, Neely JG. Patterns of facial nerve synkinesis. Laryngoscope 1996;106(12 Pt 1):1491-1496

8 Bernardes DFF, Gomez MV, Pirana S, Bento RF. Functional profile in patients with facial paralysis treated in a myofunctional approach. Pro Fono 2004;16(02):151-158

9 Devriese PP. Treatment of sequelae after facial paralysis: a global approach. J Laryngol Otol 1998;112(05):429-431

10 Diels HJ. Facial paralysis: is there a role for a therapist? Facial Plast Surg 2000;16(04):361-364

11 Goffi-Gomez MVS, Vasconcelos LGE, Bernardes DFF. Reabilitação Miofuncional da Paralisia Facial Periférica. In: Piccolotto- Ferreira. (Org.). Tratado de Fonoaudiologia. 1 ed. São Paulo: Roca; 2004:512-526

12 VanSwearingen JM, Brach JS. Changes in facial movement and synkinesis with facial neuromuscular reeducation. Plast Reconstr Surg 2003;111(07):2370-2375

13 May M, Schaitkin B. The Facial Nerve, May's Second Edition. New York: Thieme; 2000:301-318

14 Novak CB. Rehabilitation strategies for facial nerve injuries. Semin Plast Surg 2004;18(01):47-52

15 Goffi-Gomez MVS. Reabilitação miofuncional nas seqüelas da paralisia facial periférica. In Lazarini PR, Fouquet ML. Paralisia Facial. São Paulo: Lovise; 2006:149-59

16 Scriba H, Stoeckli SJ, Veraguth D, Pollak A, Fisch U. Objective evaluation of normal facial function. Ann Otol Rhinol Laryngol 1999;108(7 Pt 1):641-644

17 Coulson SE, Croxson GR, Gilleard WL. Three-dimensional quantification of the symmetry of normal facial movement. Otol Neurotol 2002;23(06):999-1002

18 Linstrom CJ. Objective facial motion analysis in patients with facial nerve dysfunction. Laryngoscope 2002;112(7 Pt 1):1129-1147

19 House JW, Brackmann DE. Facial nerve grading system. Otolaryngol Head Neck Surg 1985;93(02):146-147

20 Ross BG, Fradet G, Nedzelski JM. Development of a sensitive clinical facial grading system. Otolaryngol Head Neck Surg 1996;114(03):380-386

21 Brach JS, VanSwearingen JM. Physical therapy for facial paralysis: a tailored treatment approach. Phys Ther 1999;79(04):397-404

22 Henkelmann TC, May M. Physical Therapy and Neuromuscular Rehabilitation. IN: May M, Schaitkin B. The Facial Nerve, May's Second Edition. Thieme; 2000:301-318 
23 Nakamura K, Toda N, Sakamaki K, Kashima K, Takeda N. Biofeedback Rehabilitation for Prevention of Synkinesis After Facial Nerve Palsy. Otolaryngol Head Neck Surg 2003;128(04):539-543

24 Cronin GW, Steenerson RL. The effectiveness of neuromuscular facial retraining combined with electromyography in facial paralysis rehabilitation. Otolaryngol Head Neck Surg 2003;128(04): 534-538

25 Bernardes DFF, Franco MZ. Surface electromyography in peripheral facial paralysis patients [monography]. Escola Estadual Prof. Eurico Figueiredo (Cepef). 2008

26 van Lieshout PH, Peters HF, Starkweather CW, Hulstijn W. Physiological differences between stutterers and nonstutterers in perceptually fluent speech: EMG amplitude and duration. J Speech Hear Res 1993;36(01):55-63

27 Genaro KF. Fissura lábio palatina: atividade eletromiográfica do lábio superior. São Paulo: Tese (Doutorado) - Universidade Federal de São Paulo - Escola Paulista de Medicina; 1995:109

28 Marchiori SC, Vitti M. Eletromiografia na fala; como e porquê. IN: Marchesan I. Tópicos em Fonoaudiologia. São Paulo: Lovise; 1996

29 Perlman AL, Palmer PM, McCulloch TM, Vandaele DJ. Electromyographic activity from human laryngeal, pharyngeal, and submental muscles during swallowing. J Appl Physiol (1985) 1999;86 (05):1663-1669

30 Tomé MC, Marchiori SC. Análise eletromiográfica dos músculos orbiculares superior e inferior da boca em crianças respiradores nasais e bucais durante a emissão de sílabas. Pró-fono Revista de Atualização Científica 1999;11(01):1-7

31 Rahal ACR. Eletromiografia dos músculos masseteres e suprahióideos em mulheres com oclusão normal e com má-oclusão classe I de Angle durante a fase oral da deglutição [dissertation]. Faculdade de Medicina da Universidade de São Paulo. 2002:36

32 Rahal A, Goffi-Gomez MVS. Avaliação eletromiográfica do músculo masseter em pessoas com paralisia facial periférica de longa duração. Rev CEFAC 2007;9(02):207-212

33 Furquim de Andrade CR, Sassi FC, Juste FS, Ercolin B. Modelamento da fluência com o uso da eletromiografia de superfície: estudo piloto. Pro Fono 2008;20(02):129-132

34 Rahal A, Pierotti S. Eletromiografia e Cefalometria na Fonoaudiologia. In: Tratado de Fonoaudiologia. São Paulo: Editora Roca; 2004:237-253

35 Mitre EI, Lazarini PR, Dolci JE. Objective method for facial motricity grading in healthy individuals and in patients with unilateral peripheral facial palsy. Am J Otolaryngol 2008;29(01):51-57

36 Lazarini PR, Figueiredo MT. Testes Elétricos do Nervo Facial. In: Lazarini PR, Fouquet ML. Paralisia Facial Avaliação Tratamento Reabilitação. São Paulo: Lovise; 2006:53-63

37 Ohyama M, Obata E, Furuta S, Sakamoto K, Ohbori Y, Iwabuchi Y. Face EMG Topographic analysis of mimetic movements in patients with Bell's palsy. Acta Otolaryngol Suppl 1988;446:47-56

38 Wood DA, Hughes GB, Secic M, Good TL. Objective measurement of normal facial movement with video microscaling. Am J Otol 1994;15(01):61-65

39 Pennock JD, Johnson PC, Manders EK, VanSwearingen JM. Relationship between muscle activity of the frontalis and the associated brow displacement. Plast Reconstr Surg 1999;104(06): 1789-1797, discussion 1798-1799

40 On AY, Yaltirik HP, Kirazli Y. Agreement between clinical and electromyographic assessments during the course of peripheric facial paralysis. Clin Rehabil 2007;21(04):344-350 